\title{
First report of in vitro selection of RNA aptamers targeted to recombinant Loxosceles laeta spider toxins
}

\author{
Amalia Sapag*, Catalina Salinas-Luypaert and Carlos Constenla-Muñoz
}

\begin{abstract}
Background: Loxoscelism is the envenomation caused by the bite of Loxosceles spp. spiders. It entails severe necrotizing skin lesions, sometimes accompanied by systemic reactions and even death. There are no diagnostic means and treatment is mostly palliative. The main toxin, found in several isoforms in the venom, is sphingomyelinase D (SMD), a phospholipase that has been used to generate antibodies intended for medical applications. Nucleic acid aptamers are a promising alternative to antibodies. Aptamers may be isolated from a combinatorial mixture of oligonucleotides by iterative selection of those that bind to the target. In this work, two Loxosceles laeta SMD isoforms, LI1 and LI2, were produced in bacteria and used as targets with the aim of identifying RNA aptamers that inhibit sphingomyelinase activity.
\end{abstract}

Results: Six RNA aptamers capable of eliciting partial but statistically significant inhibitions of the sphingomyelinase activity of recombinant SMD-LI1 and SMD-LI2 were obtained: four aptamers exert 17\% inhibition of SMD-LI1, while two aptamers result in 25\% inhibition of SMD-LI2 and 18\% cross inhibition of SMD-LI1.

Conclusions: This work is the first attempt to obtain aptamers with therapeutic and diagnostic potential for loxoscelism and provides an initial platform to undertake the development of novel anti Loxosceles venom agents.

Keywords: Antivenom, Loxosceles laeta, RNA aptamers, SELEX, SMD-LI1, SMD-LI2, Sphingomyelinase D

\section{Background}

The envenomation resulting from the bite of spiders of the genus Loxosceles is called loxoscelism [1-3]. It is characterized by severe necrotizing wounds in the skin (cutaneous loxoscelism), which are sometimes accompanied by systemic reactions that can lead to death (viscerocutaneous loxoscelism). A distinctive skin ulcer develops rapidly, within days, but may take months to heal leaving behind disfiguring scars. In the more severe systemic form of poisoning, which has a higher incidence in children, intravascular hemolysis may cause anemia and acute renal failure within 72 hours. There are no diagnostic means available and treatment is mainly palliative.

Loxosceles spiders are mostly found in the warm and tropical climate areas of the Americas. Loxosceles reclusa

\footnotetext{
* Correspondence: asapag@uchile.cl

Laboratory of Gene Pharmacotherapy, Department of Pharmacological and Toxicological Chemistry, Faculty of Chemical and Pharmaceutical Sciences, Universidad de Chile, Sergio Livingstone Pohlhammer 1007, Independencia, Santiago 838-0492, Chile
}

(brown recluse spider) and $L$. deserta account for most cases of loxoscelism in the United States. In South America, the three major species responsible for envenomation are L. intermedia, L. gaucho and L. laeta [2]. The frequency of viscerocutaneous loxoscelism is higher $(\sim 15 \%)$ in geographic areas where L. laeta is the predominant species, such as Chile [4], Peru, and certain regions of Brazil [5]. The actual incidence of envenomation is not known because the spider is seldom captured and presented at the time of medical evaluation.

The venom of Loxosceles spiders contains several toxins [6], including multiple isoforms of sphingomyelinase D (SMD) [7], a phospholipase capable of eliciting biological damage similar to that of whole venom, i.e., dermonecrosis, platelet aggregation and hemolysis [7-9]. Sphingomyelinase D has two known substrates: sphingomyelins, which are abundant in cell membranes -especially in skin and erythrocytes - and give rise to phosphoceramides, and lysophosphatidylcholine, a substrate abundant in plasma, which generates lysophosphatidic acid, 
a pleiotropic mediator [10]. A number of Loxosceles SMDs have been cloned, sequenced and characterized, such as several from L. laeta [8,11-13], L. intermedia [14], L. reclusa and L. boneti [15].

Although there are several Loxosceles antivenoms commercially available $[2,16]$, their safety and efficacy remain controversial. Given that equine hyperimmune sera may cause allergic reactions, therapeutic antibodies obtained against recombinant SMDs $[13,17]$ are under preclinical development. For example, an antiserum raised against a toxic recombinant SMD from $L$. laeta can block the skin lesion caused by whole $L$. laeta venom in rabbits [8]; similar immunoprotection using a nontoxic recombinant SMD has been reported [11]. Monoclonal antibodies are also capable of neutralizing dermonecrotic and lethality effects of Loxosceles venoms but do not always confer cross species protection $[18,19]$. Antigenic cross reactivity [e.g., 13,17,20-22] is relevant to the development of wide spectrum Loxosceles antivenoms. Although significant reactivity and dermonecrotic protection has been reported between some species, Olvera et al. [13] suggest that the sequence divergence of the L. laeta SMDs (e.g., only $40 \%$ identity with $L$. boneti SMD) may account for their lack of in vitro and in vivo responsiveness to cross species antisera. Thus, treatment for envenomation by L. laeta requires special attention.

In spite of their widespread use in therapeutics, antibodies have limitations such as the requirement of live animals for their development, immunogenicity, limited stability, and elevated costs. Nucleic acid aptamers overcome these limitations and are thus a promising alternative to antibodies. RNA or DNA oligonucleotides that have been selected for their ability to bind to other molecules with high affinity and high specificity have great applicability in therapeutics [23]. In particular, an aptamer having the capacity to bind to a Loxosceles sphingomyelinase D and abolish its enzymatic activity would have potential as an antidote for loxoscelism. Aptamers may be obtained by an iterative in vitro selection strategy (Figure 1) known as "systematic evolution of ligands by exponential enrichment" (SELEX) (reviewed by Stoltenburg et al. [24]). An oligonucleotide library of $\geq 10^{13}$ different sequences, typically $\leq 100$ nucleotides long, is subjected to in vitro selection based on the desired biological activity, usually the affinity for a particular target. The molecules which satisfy the selection criterion are separated from those that do not and, following an amplification step, are subjected to a new selection round; this cycle is usually performed 4-20 times. Amplification is done by the polymerase chain reaction (PCR) or, in the case of RNA aptamers, by reverse transcription, PCR, and in vitro transcription. Finally, aptamers are cloned, sequenced, and tested individually for binding or other biological activity. In this work, RNA aptamers selected for binding to L. laeta SMD isoforms Ll1 and Ll2 [13], which differ in 47 of 285 amino acids,

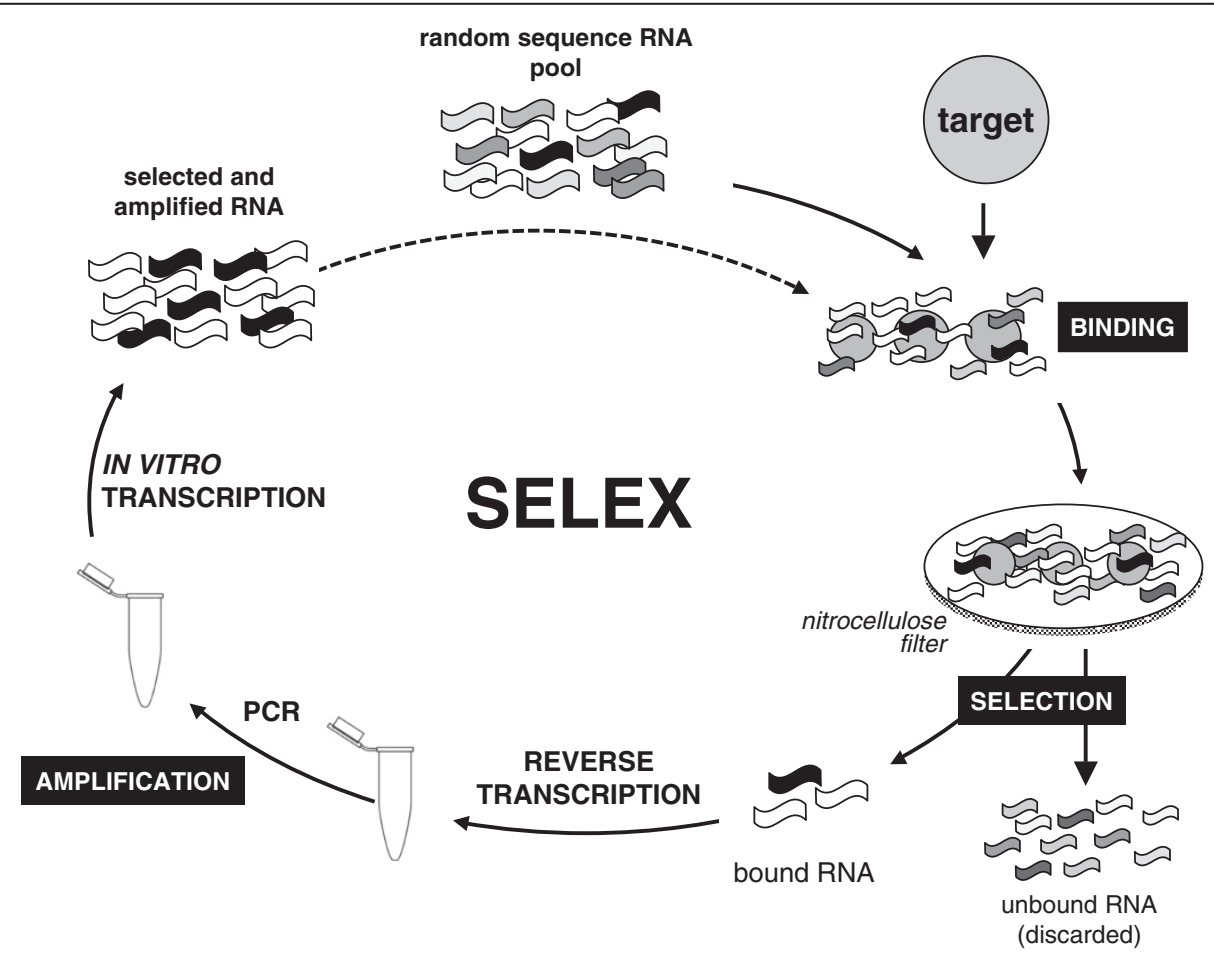

Figure 1 Iterative in vitro selection of RNA aptamers (SELEX). 
were obtained and analyzed for their capacity to inhibit sphingomyelinase activity.

\section{Results}

Selection of aptamers capable of binding to Loxosceles laeta SMDs

RNAs that bind to either isoform Ll1 or Ll2 of sphingomyelinase D were obtained by selection from starting random RNA pools having $\sim 10^{13}$ different sequences. For SMD-Ll1, two independent iterative selection (SELEX) processes, $\mathrm{E}$ and $\mathrm{F}$, were performed at protein:RNA ratios of 1:10 and 1:5 using 10 or 20 pmoles of SMD-Ll1 respectively and 100 pmoles of RNA. Identical initial pools of RNA (named s0: selected 0 times) were used for $E$ and F. Twelve selection cycles were carried out for SELEX E and ten for SELEX F. For SMD-Ll2, an iterative selection of 12 cycles, called SELEX G, was performed at a protein: RNA ratio of 1:10 using 10 pmoles of SMD-Ll2. The RNA molecules of the initial pool (s0) were different from those used for $\mathrm{E}$ and $\mathrm{F}$.

\section{Inhibition of sphingomyelinase activity by pools of selected RNA}

The sphingomyelinase activity of recombinant toxins was measured in the presence of the RNA recovered from each selection round of SELEX E, F, and G (s1 through s12) to determine its apparent inhibitory capacity; assays were done using protein:RNA molar ratios of 1:1. In all cases (E, F and G) (Figure 2) sphingomyelinase activity in the presence of RNA from the initial cycles (s1-s3) was greater than that of protein alone. SELEX E (Ll1) and SELEX G (Ll2) behaved similarly in that the activity obtained with s1 RNA dropped gradually along the first 4-8 cycles followed by an increase in activity in cycle 9 and thereon (more pronounced and significant in E). For SMD-Ll1 (SELEX E), activity reaches a 9\% maximum reduction on $\mathrm{s} 8$ (25\% reduction between $\mathrm{s} 1$ and $\mathrm{s} 8$, $\mathrm{P}<0.001)$. For SMD-Ll2, activity also reaches a maximum reduction (3.3\%) on $\mathrm{s} 8$ (17.6\% reduction between $\mathrm{s} 1$ and s8, $\mathrm{P}<0.001$ ). Accordingly, RNA pools Es8 and Gs8 were chosen for cloning to isolate and characterize individual aptamers with therapeutic potential. RNA pools Es12 and Gs12 were also cloned; their binding affinity is expected to be greater than that of $\mathrm{s} 8$ RNAs and, therefore, they may have greater potential for diagnostics. SELEX F (Ll1), in which the selection pressure was less than that applied in SELEX E, allowed reaching a $25 \%$ reduction $(\mathrm{P}<0.001)$ of SMD-Ll1 activity with s10 RNA (last round performed), suggesting that even more profound effects might be attained in additional selection rounds.

\section{Sequence characterization of individual aptamers}

The DNA pools encoding RNA molecules from selection rounds Es8, Es12 and Fs10 (selected for binding to
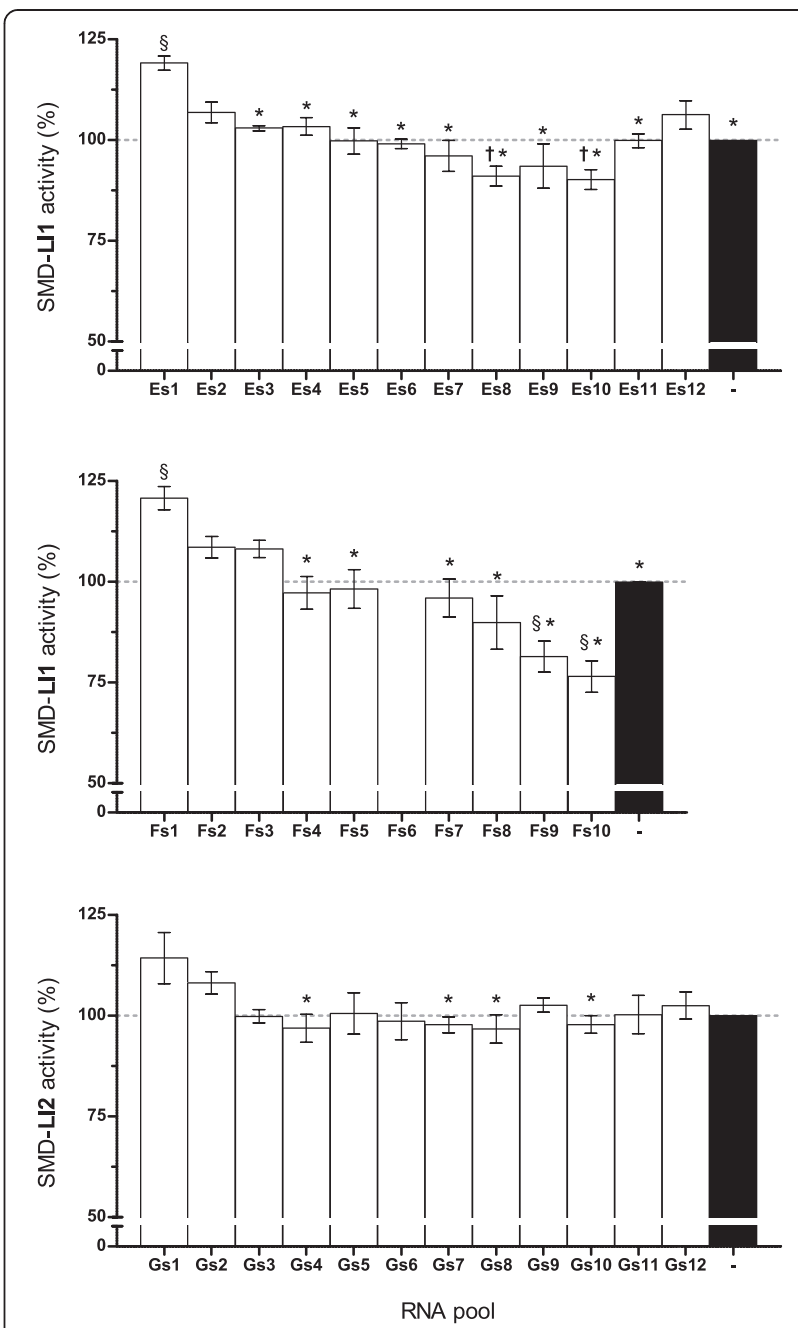

Figure 2 Effect of pools of RNA selected for binding to SMD-LI1 (SELEX E and SELEX F) or to SMD-LI2 (SELEX G) on the activity of their cognate enzyme. Activity of SMD-LI1 or SMD-LI2 in the presence of all pools of RNA obtained from SELEX E (top, LI1), SELEX F (middle, LI1) or SELEX G (bottom, LI2) at SMD:RNA molar ratios of 1:1 was calculated from fluorescence measurements. SMD activity is expressed as percent of the fluorescence counts obtained with each protein in the absence of RNA (black bars). Data shown are averages of three experiments $(n=3)$, each in triplicate (SELEX E and F) or duplicate (SELEX G), \pm standard error of the mean (SEM). Significant differences $(P<0.001)$, determined by ANOVA of repeated measures and the Tukey post-test, are shown as $\S$, relative to protein alone in the absence of $\mathrm{RNA}$; ${ }^{*}$, relative to $\mathrm{s} 1$; and $t$, relative to $s 12$.

SMD-L11), and selection rounds Gs8 and Gs12 (selected for binding to SMD-Ll2), were cloned in pUC19. Individual clones ( $\sim 50$ from each pool) were sequenced, and reliable sequences (on average 90\%) were analyzed to establish families of related aptamer sequences. Taking into account the 60 random nucleotides in the center of each 107 nt aptamer, sequence identity within a family was $>92 \%$ (i.e., less than $5 \mathrm{nt}$ differed between family members, typically 2 or 3 ), while identity between 
families was $<60 \%$. Sequences entirely different from all others in that cohort were termed orphan sequences.

Analysis of cohort Es8 revealed 49/54 clones (91\%) grouped in 6 families, and 5 orphan sequences; of 26 unique sequences the most frequent one was found in 9 clones. Similarly, cohort Es12 had 36/40 clones (90\%) belonging to 7 sequence families, and 4 orphan sequences. Of 24 unique sequences the most frequent one was found in 5 clones, and 7 (29\%) were also present in cohort Es8. Cohort Fs10 had 42/47 clones (89\%) that could be grouped in 9 sequence families, and 5 orphan sequences. Of 32 unique sequences the most frequent one was found in 6 clones, and 11 (34\%) had already been found in SELEX E: Fs10 shares 7 sequences with both Es8 and Es12, 2 with Es8 only, and 2 with Es12 only. Thus, independent selection processes $\mathrm{E}$ and $\mathrm{F}$, both performed with SMD-Ll1 and starting from the same $\sim 10^{13}$ RNA variants, led to common aptamers.

As for the iterative selection performed by affinity for SMD-Ll2, analysis of cohort Gs8 revealed 35/49 clones (71\%) grouped in 11 sequence families, and 14 orphan sequences; of 37 unique sequences the most frequent one was found in 8 clones. Similarly, cohort Gs12 had $42 / 52$ clones (82\%) belonging to 9 sequence families, and 10 orphan sequences. Of 29 unique sequences the most frequent one was found in 13 clones, and 8 (28\%) were also present in cohort Gs8.

As expected, no sequences were found to be common between the SMD-Ll1 and the SMD-Ll2 selections; SELEX E (and F) and SELEX G were initiated with RNA pools that were theoretically entirely different given that they originated from different aliquots of the random oligonucleotide synthesis. Es8, Fs10 and Gs12 were chosen for functional characterization of individual aptamers.

\section{Functional characterization of individual aptamers}

All unique aptamers (either orphans or belonging to sequence families) found in cohorts Es8 and Gs12 were tested for their capacity to inhibit the enzymatic activity of their cognate sphingomyelinase; Fs10 aptamers not found in Es8 were also assayed. The SMD:RNA molar ratio used in this inhibition assay (Figure 3) was 1:10, both for individual aptamers as well as for their pools of origin.

In cohort Es8 (Figure 3, top panel) there were four aptamers that elicited $16-17 \%$ inhibition of SMD-Ll1 $(\mathrm{P}<0.001)$; none of the orphan aptamers elicited a significant reduction in sphingomyelinase activity. The sequences of these leading aptamers, Es8-6 (family \#6), Es8-7 and Es8-9 (family \#2), and Es8-20 (family \#1) were not the most abundant in the group, but three of them belong to the two most populated families in Es8. Three of these aptamers arose independently in both SELEX E and SELEX F, namely, Es8-6, Es8-7, and Es8-20, one from each family. These aptamers elicit inhibitions that are very similar to or greater than the apparent inhibitory capacity of the Es8 RNA pool or the Fs10 pool ( 17\% vs. $15 \%$ or $3 \%$ respectively). None of the aptamers unique to Fs10 displayed significant reductions of SMD-Ll1 activity (Figure 3, middle panel).

In cohort Gs12 (Figure 3, bottom panel) there were two aptamers that elicited $\sim 23 \%$ and $\sim 26 \%$ inhibition of SMD-Ll2 $(\mathrm{P}<0.05$ and $\mathrm{P}<0.01)$; none of the orphan aptamers elicited significant reductions in sphingomyelinase activity (data not shown). Although the two leading aptamers -Gs12-62 (family \#2) and Gs12-70 (family \#3)were found in only one copy amongst the 52 clones sequenced, they belong to the second and third most populated families in Gs12, two families which had already arisen in Gs8. As expected for some individual aptamers, these leaders elicit inhibitions greater than that of the Gs12 RNA pool ( 25\% vs. 12\%).

Worth noting is that RNA pools elicit different inhibitions of sphingomyelinase activity depending on the SMD:RNA ratio used in the assay, 1:1 (Figure 2) or 1:10 (Figure 3). This may be explained by the fact that these are pools of many RNAs, each having a unique combination of binding affinity and inhibitory capacity and each represented in a different number of copies; the possible RNA-RNA interactions in each pool are likewise unique. Depending on which set of aptamers coexist in a given pool, the overall behavior is as likely to change in one direction or the other when the SMD:RNA ratio is changed.

An interesting question to address is whether the best two inhibitory aptamers, those selected for binding to SMD-Ll2, are capable of inhibiting a noncognate SMD. Cross activity experiments (Figure 4 ) show that aptamers Gs12-62 and Gs12-70 clearly exert a significant inhibitory effect on SMD-Ll1 ( 18\%).

\section{Discussion}

The original gene constructs from which SMD-Ll1 and SMD-Ll2 were produced in E. coli [13], were not available for this work. Hence, de novo synthesis was adopted to generate the cDNAs. Once cloned in the expression plasmid pQE30-Xa, akin to what was reported in the literature, no bacterial production of the enzymes was observed. However, recloning in a different vector yielded the recombinant proteins. Specific activities $( \pm \mathrm{SD})$ were approximately $17 \pm 6 \mathrm{U} / \mathrm{mg}$ for SMD-Ll1 and $159 \pm 9 \mathrm{U} / \mathrm{mg}$ for SMD-L12, somewhat lower than those reported by Olvera et al. [13] for recombinant SMD-Ll1 (also tagged in the $\mathrm{N}$ terminus), and for SMD-Ll2 tagged in the C terminus, $56.8 \pm 9.9$ and $228.2 \pm 58.7 \mathrm{U} / \mathrm{mg}$ respectively. Thus, this is the first report of an active recombinant SMD-Ll2 bearing the histidine tag on the $\mathrm{N}$ terminus; this variant was expected to be active because the crystallographic data available [25] show both protein ends 

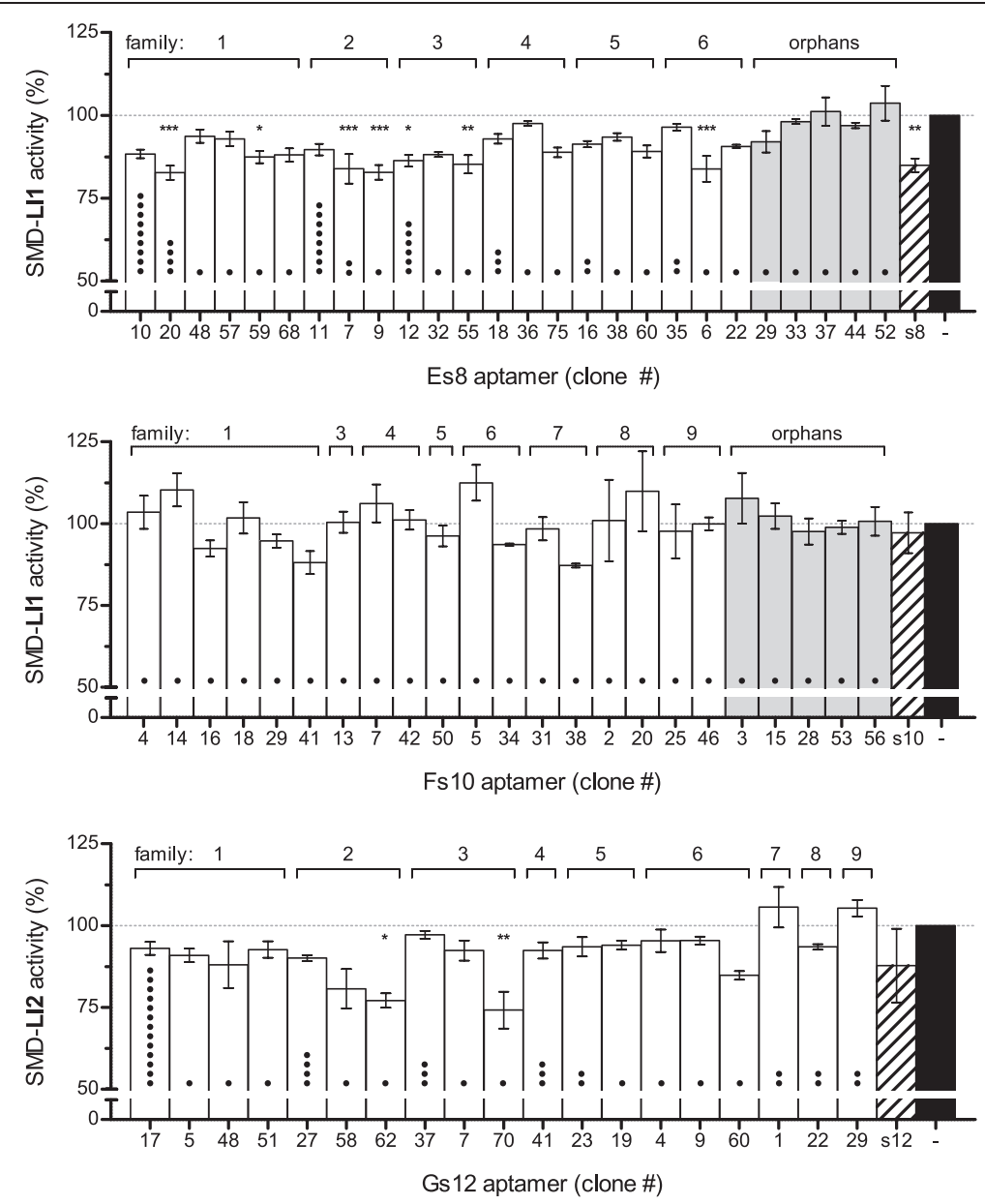

Figure 3 Effect of individual RNA aptamers from the Es8, Fs10, and Gs12 cohorts on cognate SMD activity. Activity of SMD-LI1 and SMD-LI2 in the presence of RNA aptamers found in cohorts Es8 (top, LI1), Fs10 (middle, LI1), and Gs12 (bottom, LI2) at SMD:RNA molar ratios of 1:10 was calculated from fluorescence measurements. SMD activity is expressed as percent of the fluorescence counts obtained with each protein in the absence of RNA (black bars). Data shown are averages of three experiments $(n=3)$, each in triplicate, \pm SEM. The inhibitory effects of the RNA pools of origin are shown in hatched bars. The dots (•) in each bar represent the number of clones that were found to have the same sequence as that specific clone. Clones belonging to families are shown in white bars and orphan clones are shown in grey. Significant inhibitions relative to protein alone were determined by an ANOVA of repeated measures and the Tukey post-test (*** $P<0.001,{ }^{* *} P<0.01,{ }^{*} P<0.05$ ).

unencumbered. Initial attempts to remove the histidine tags with factor Xa to preclude any interference during SELEX were not quantitative but optimization efforts were not pursued because preliminary studies showed that aptamer pools with inhibitory activity were obtained, suggesting that the tags did not hinder selection of RNA aptamers based on their recognition by the SMD portion of the recombinant proteins.

The sphingomyelinase activity inhibition data for selected RNA pools show that there are statistically significant changes in RNA behavior as selection rounds proceed, suggesting that selection took place along the process, even though apparent affinity of selected RNA pools was not measured. When selection pressure was defined by a 1:10 protein:RNA molar ratio, a net inhibition of SMD activity became apparent with s4 RNA, reached a maximum with s8 RNA, and was lost or remained stagnant ( $E$ and $G$ respectively) as selection proceeded, that is, as apparent affinity is expected to increase. A reasonable explanation for this behavior, as well as for the activating effect seen with RNA from the initial rounds (s1-s3), is that both activating and inhibiting aptamers exist in the selected pools; given that the selection was carried out by affinity, some activating or noneffector aptamers may bind more tightly than inhibitory aptamers, eventually displacing the latter. Hence, maximum affinity pools are probably not enriched in the best sphingomyelinase inhibitors. It follows that if the selection processes had been monitored by affinity the best inhibitor pools might have been overlooked. Given that a good inhibitor necessarily has to bind, this work suggests that a feasible route to obtain an aptamer with good therapeutic potential is 


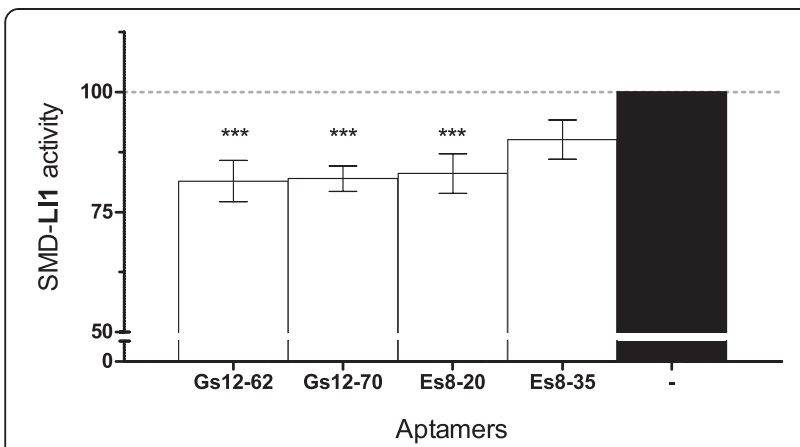

Figure 4 Cross effects of leader Gs12 aptamers on SMD-LI1 activity. Activity of SMD-LI1 in the presence of RNA aptamers selected for binding to SMD-LI2 (Gs12-62 and Gs12-70) at SMD:RNA molar ratios of 1:10 was calculated from fluorescence measurements. SMD activity is expressed as percent of the fluorescence counts obtained with SMD-LI1 in the absence of RNA (black bar). The effects of control aptamers selected for binding to SMD-LI1 are also shown: Es8-20 (inhibitory RNA), and Es8-35 (noninhibitory RNA). Data shown are averages of six experiments $(n=6)$ except for Es8-35 $(n=3)$, each in triplicate, \pm SEM. Significant inhibitions relative to protein alone were determined for data in $n=6$ by an ANOVA of repeated measures and the Tukey post-test (*** $P<0.001)$.

selection by affinity, followed by identification of inhibitors, and then by optimization of inhibition and/or binding capacities.

The maximum inhibitory capacity obtained was $\sim 26 \%$ (aptamer Gs12-70), far from the full inhibition that is naturally desirable in an antidote. Bearing in mind that selections were done on the basis of binding - not inhibitory capacity - several additional reasons may explain this outcome. First, as seen from comparing selection processes $E$ and $F$ (Figure 2), a less competitive and slower SELEX may be better; a protein (SMD-Ll1):RNA ratio of 1:5 allowed the Fs10 pool to exert an inhibition of $25 \%$, greater than the maximum inhibition obtained when the selection ratio was 1:10 (9\% for Es8). Thus, many good candidates may have been lost in the early stages of the $E$ process. Second, sequencing a greater number of clones per cohort, e.g., 100 clones, might have allowed the identification of stronger inhibitors. Third, although the initial DNA pool (s0) was subjected to digestion with $\mathrm{XbaI}$ to avoid selecting clones that would be lost in the final cloning step, this was not done with HindIII, the other restriction enzyme used for cloning. Thus, good inhibitors might have been lost upon cloning. These observations offer guidelines for future efforts to obtain aptamer antidotes for these SMDs. An alternative route to obtaining aptamers with greater inhibitory capacity is to optimize the effects of the best available (partially inhibitory) RNAs; the finding that two aptamers that differ solely in one nucleotide, e.g., Gs12-37 and Gs12-70, have different inhibitory capacities, suggests that mutagenesis of leader aptamers might be worthwhile. A SELEX approach starting from a leader RNA subjected to mutagenesis in its entire sequence or in only one or several nucleotides, may be considered.

\section{Conclusions}

The application of SELEX technology to obtain therapeutic or diagnostic agents for biological toxins has been reviewed recently [26]. It is a very promising approach given the advantages inherent to the small size and chemical nature of nucleic acid aptamers when compared to antibodies. Additionally, nucleic acid aptamers may be coupled to various detection methods and are thus very versatile as diagnostic agents [27]. In this work, six RNA aptamers capable of partial inhibition (16-26\%) of two Loxosceles laeta sphingomyelinases, SMD-L11 and SMDLl2, were obtained by iterative selection, constituting an initial platform for the development of novel nucleic acid drugs that may be both safe and specific for the venom of the most dangerous species of the Loxosceles spiders. To our knowledge, this is the first attempt to obtain aptamers with therapeutic and diagnostic potential for loxoscelism.

\section{Methods}

\section{Synthesis of CDNAs and gene constructs encoding} Loxosceles laeta SMD isoforms

Gene expression constructs encoding recombinant $L$. laeta SMDs Ll1 and Ll2 were generated. The 858 bp cDNAs for the mature form of SMD-Ll1 [GenBank:DQ369999] and SMD-L12 [GenBank:DQ37000] [13] were assembled in vitro by polymerase chain assembly, which employs long synthetic oligonucleotides as starting material for extension and amplification reactions [28]; Pfu DNA polymerase (Fermentas) was used. For each SMD, 22 overlapping oligonucleotides were designed (overlaps of $18 \mathrm{nts}$ ): 2 external oligonucleotides (33 nts each) and 20 internal oligonucleotides (59 nts each), all synthesized by Integrated DNA Technologies (IDT). Cloning schemes demanded introducing single nucleotide modifications as well as the addition of AAG CTT ACT G to the 3 ' end to incorporate a HindIII site. Specifically, for SMD-Ll1, a nonsilent mutation $26 \mathrm{~A}>\mathrm{T}$ (N9I), and four silent mutations $(36 \mathrm{~T}>\mathrm{C}, 462 \mathrm{~T}>\mathrm{C}, 618 \mathrm{C}>\mathrm{T}, 837 \mathrm{~A}>\mathrm{T})$; for SMDLl2, five silent mutations $(141 \mathrm{~T}>\mathrm{C}, 300 \mathrm{~T}>\mathrm{C}, 462 \mathrm{~T}>\mathrm{C}$, $618 \mathrm{C}>\mathrm{T}, 837 \mathrm{~A}>\mathrm{T})$. Each cDNA was assembled in two halves from which full-length sequences $(868 \mathrm{bp})$ were obtained. Amplicons were purified from agarose gels with the Wizard SV Gel and PCR Clean-up System (Promega). The sequences required for protein production and purification were provided by directional cloning (blunt end/ HindIII) in pQE30-Xa (Qiagen) (StuI, Klenow, HindIII). The EcoRI-HindIII fragments from these intermediate constructs contained sequences encoding a ribosome binding site, an initiation codon, and a recombinant protein having a $\mathrm{His}_{6}$ tag, the four residues required for 
proteolytic cleavage by factor $\mathrm{Xa}$, and a mature SMD. These fragments were transferred to pGEM-3Zf $(+)$ (Promega) downstream of the T7 RNA polymerase promoter (EcoRI/HindIII) to generate final gene expression constructs pCC-8 and pCSL-2 encoding SMD-Ll1 and SMD-Ll2 respectively. Plasmids were purified from $E$. coli DH5 $\alpha$ cultures (Wizard Plus SV Minipreps DNA Purification System, Promega) and constructs were confirmed by sequencing (CESAT, Universidad de Chile).

\section{Production and purification of recombinant SMD-LI1 and SMD-LI2}

Recombinant SMD-L11 and SMD-L12 were produced in E. coli Origami B (DE3) (Novagen) transformed with pCC-8 or pCSL-2 respectively. Luria broth cultures (50 mL, $100 \mu \mathrm{g} / \mathrm{mL}$ ampicillin) were grown in $250 \mathrm{~mL}$ flasks at $37^{\circ} \mathrm{C}$ and $250 \mathrm{rpm}$ to an $\mathrm{A}_{600}$ of 0.5-0.7 (4.5-5 h). Gene expression was induced with $1 \mathrm{mM}$ IPTG and, after $16 \mathrm{~h}$ of growth, $35 \mathrm{~mL}$ of culture were harvested by centrifugation at $4^{\circ} \mathrm{C}$. Cells were resuspended in $5 \mathrm{~mL}$ of NPI-10 (50 mM NaH${ }_{2} \mathrm{PO}_{4}, 300 \mathrm{mM} \mathrm{NaCl}, 10 \mathrm{mM}$ imidazole) and lysed by $\geq 4$ freeze-thaw cycles $\left(-80^{\circ} \mathrm{C}\right.$ freezer $/ 37^{\circ} \mathrm{C}$ water bath, $30 \mathrm{~min}$ each). DNaseI was added $(10 \mu \mathrm{g} / \mathrm{mL})$ and lysates were incubated $30 \mathrm{~min}$ in a $37^{\circ} \mathrm{C}$ water bath, clarified by centrifugation $\left(12857 \times \mathrm{g}, 30 \mathrm{~min}, 4^{\circ} \mathrm{C}\right)$ and filtered through polyethersulfone membranes (Millex GP, $0.22 \mu \mathrm{m}$, Millipore).

Recombinant proteins were purified by affinity chromatography using $1 \mathrm{~mL}$ size Ni-NTA Superflow cartridges (Qiagen). After loading, columns were washed with 10 volumes of NPI-20 (20 mM imidazole) and bound proteins were eluted with $10 \mathrm{~mL}$ of NPI-250 (250 mM imidazole) in $0.5-1 \mathrm{~mL}$ fractions. Purifications were monitored in $0.1 \%$ SDS- $10 \%$ polyacrylamide gels and pure fractions were dialysed in $3 \mathrm{~mL}$ Slide-A-Lyzer cassettes (10,000 MWCO) (Pierce) against $50 \mathrm{mM}$ Tris$\mathrm{HCl} \mathrm{pH} 8$ (Figure 5A). The Micro BCA Protein Assay Kit (Pierce) was used for quantification in flat bottom clear 96 well plates (Costar 3635) using a bovine serum albumin (BSA) standard curve; absorbance was measured after $2 \mathrm{~h}$ at $37^{\circ} \mathrm{C}$ in a Victor X3 (Perkin Elmer) plate reader (560 \pm $8 \mathrm{~nm}$ ). Approximate yields were $6 \mathrm{mg}$ for SMD-Ll1 and $0.5 \mathrm{mg}$ for SMD-Ll2. Both 306 aa recombinant proteins, of 34.2 and $34.8 \mathrm{kDa}$ respectively, have a synthetic 21 aa peptide (MRGSH ${ }_{6}$ GSGSGSGIEGR) preceding the 285 residues of mature toxin sequence.

\section{Sphingomyelinase activity measurements}

Activity of recombinant proteins was measured in $100 \mathrm{mM}$ Tris- $\mathrm{HCl} \mathrm{pH}$ 7.4, $10 \mathrm{mM} \mathrm{MgCl}_{2}$ with the Amplex Red Sphingomyelinase Assay Kit (Invitrogen) in $200 \mu \mathrm{L}$ reactions $(100 \mu \mathrm{L}$ of sample plus $100 \mu \mathrm{L}$ working solution). Fluorescence of resorufin was read in white flat bottom 96 well plates (Nunc 236108) in a Victor X3

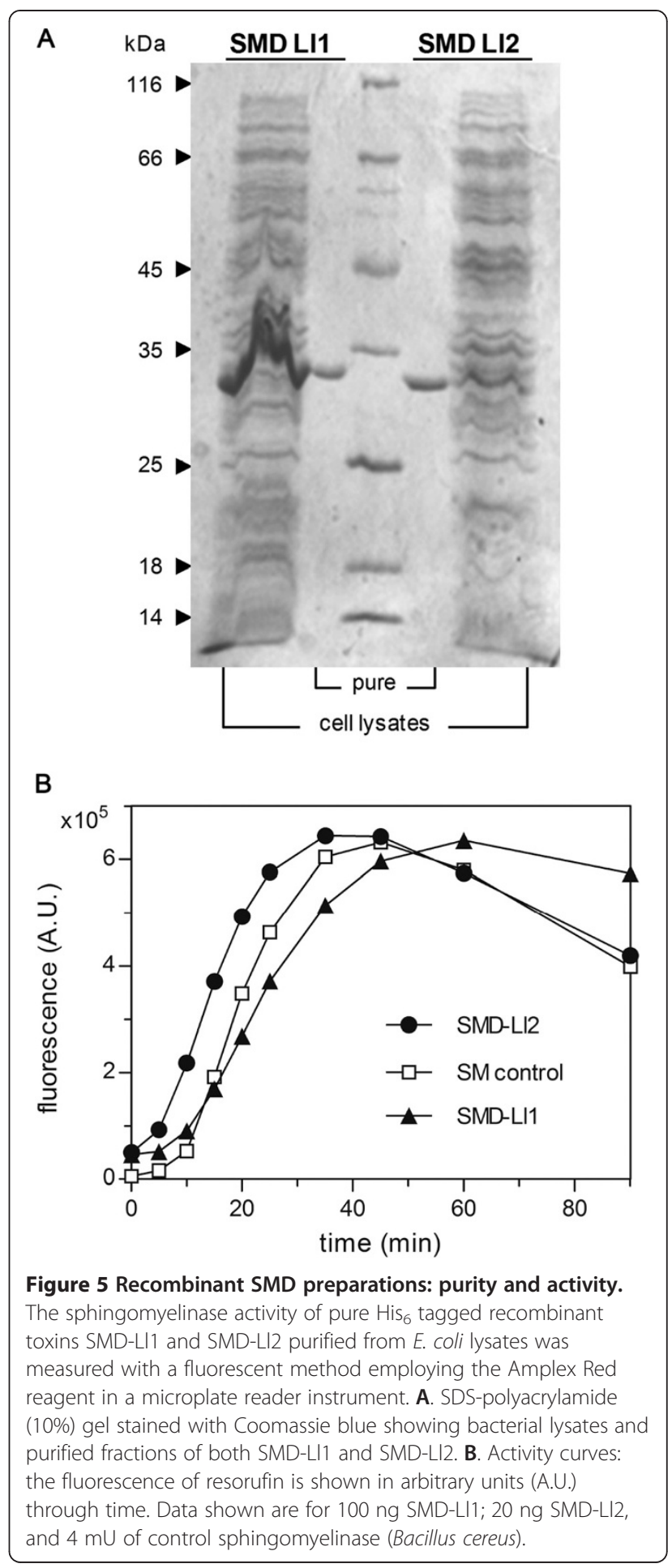

instrument for 60-90 minutes (excitation: $544 \pm 15 \mathrm{~nm}$, emission: $590 \pm 20 \mathrm{~nm}$ ). A linear behavior between activity and fluorescence was generally obtained throughout the first 20 minutes (Figure 5B) with 100 and $20 \mathrm{ng}$ of SMD-Ll1 and SMD-Ll2 respectively; activities were calculated at 10,15 or 20 minutes. 


\section{Generation of the initial random RNA pool}

Suitable templates for in vitro transcription were generated as follows (Figure 6). A long DNA oligonucleotide (TG-503, 96-mer) having a 60 nt center of random sequence flanked by segments $\mathrm{A}$ and $\mathrm{B}$ was synthesized (GAA GTT TGA TCA TGG CTC N ${ }_{(60)}$ GGA TAT CTG AGT CGA GAT). A full-length degenerate duplex (133 bp) was obtained by PCR amplification of 10 pmoles of TG-503 (5 U Biolase Taq DNA polymerase (Bioline), $200 \mu \mathrm{M}$ each dNTP, $10 \%$ dimethylsulfoxide, $1.5 \mathrm{mM}$ $\mathrm{MgCl}_{2} ; 2$ min $94^{\circ} \mathrm{C} / 30$ cycles of $30 \mathrm{sec} 94^{\circ} \mathrm{C}, 30 \mathrm{sec}$ $65^{\circ} \mathrm{C}, 2 \min 72^{\circ} \mathrm{C} / 10 \min 72^{\circ} \mathrm{C}$ ) using primers TG-504 and TG-505 (100 pmoles each) in ten $50 \mu \mathrm{L}$ reactions. Oligonucleotides TG-503, 504 and 505 (IDT) were designed according to Sapag and Draper [29] with modifications. Primer TG-504 (CAG TAA GCT TAA TAC GAC TCA CTA TAG GGA AGT TTG ATC ATG GCT C, 46-mer) anneals to flanking sequence $A$, provides the T7 phage RNA polymerase promoter and a HindIII recognition sequence, while primer TG-505 (CAG TTC TAG ATC TCG ACT CAG ATA TCC, 27-mer) anneals to flanking sequence $\mathrm{B}$ and carries an $\mathrm{XbaI}$ recognition sequence. The degenerate amplicon was digested with $\mathrm{XbaI}$ and purified from a 3\% Nusieve agarose gel.
Transcription was done at $37^{\circ} \mathrm{C}$ in $50 \mu \mathrm{L}$ reactions for 2 hours using $\sim 250 \mathrm{ng}$ of degenerate duplex, $20 \mathrm{U} \mathrm{T7}$ RNA polymerase (Fermentas), and $2 \mathrm{mM}$ each NTP. Products were precipitated and separated by electrophoresis in $8 \%$ denaturing ( $50 \%$ urea $\mathrm{w} / \mathrm{v}$ ) polyacrylamide gels run at $17 \mathrm{~W}$ for $1 \mathrm{~h}$. Full-length RNAs were visualized by UV-shadowing, bands were excised and soaked in water overnight at $37^{\circ} \mathrm{C}$, and RNAs (102 nt) were concentrated with Amicon Ultra (2 mL $30 \mathrm{~K})$ centrifugal filters. RNA concentrations were measured by absorbance at $260 \mathrm{~nm}$.

\section{Selection cycles}

Protein and RNA were prepared separately for binding in equal volumes $(25 \mu \mathrm{L})$ prior to mixing $(50 \mu \mathrm{L})$. Typically, 10 pmoles of toxin $(\sim 0.3 \mu \mathrm{g})$ and 100 pmoles of RNA $(\sim 3.3 \mu \mathrm{g})$ were used (1:10 molar ratio). The protein was incubated in $100 \mathrm{mM}$ Tris- $\mathrm{HCl} \mathrm{pH} 7.4$ for $20 \mathrm{~min}$ at $37^{\circ} \mathrm{C}$ and $10 \mathrm{~min}$ at room temperature. The RNA was renatured in $100 \mathrm{mM}$ Tris- $\mathrm{HCl} \mathrm{pH} 7.4$ and $20 \mathrm{mM} \mathrm{MgCl}_{2}$ for $20 \mathrm{~min}$ at $42^{\circ} \mathrm{C}$ and $10 \mathrm{~min}$ at room temperature. After combining the two, binding conditions being $100 \mathrm{mM}$ Tris- $\mathrm{HCl} \mathrm{pH} 7.4$ and $10 \mathrm{mM} \mathrm{MgCl} 2$, mixtures were incubated for 10 minutes at room temperature. Filtration through nitrocellulose membranes (Whatman \# 7182-002,

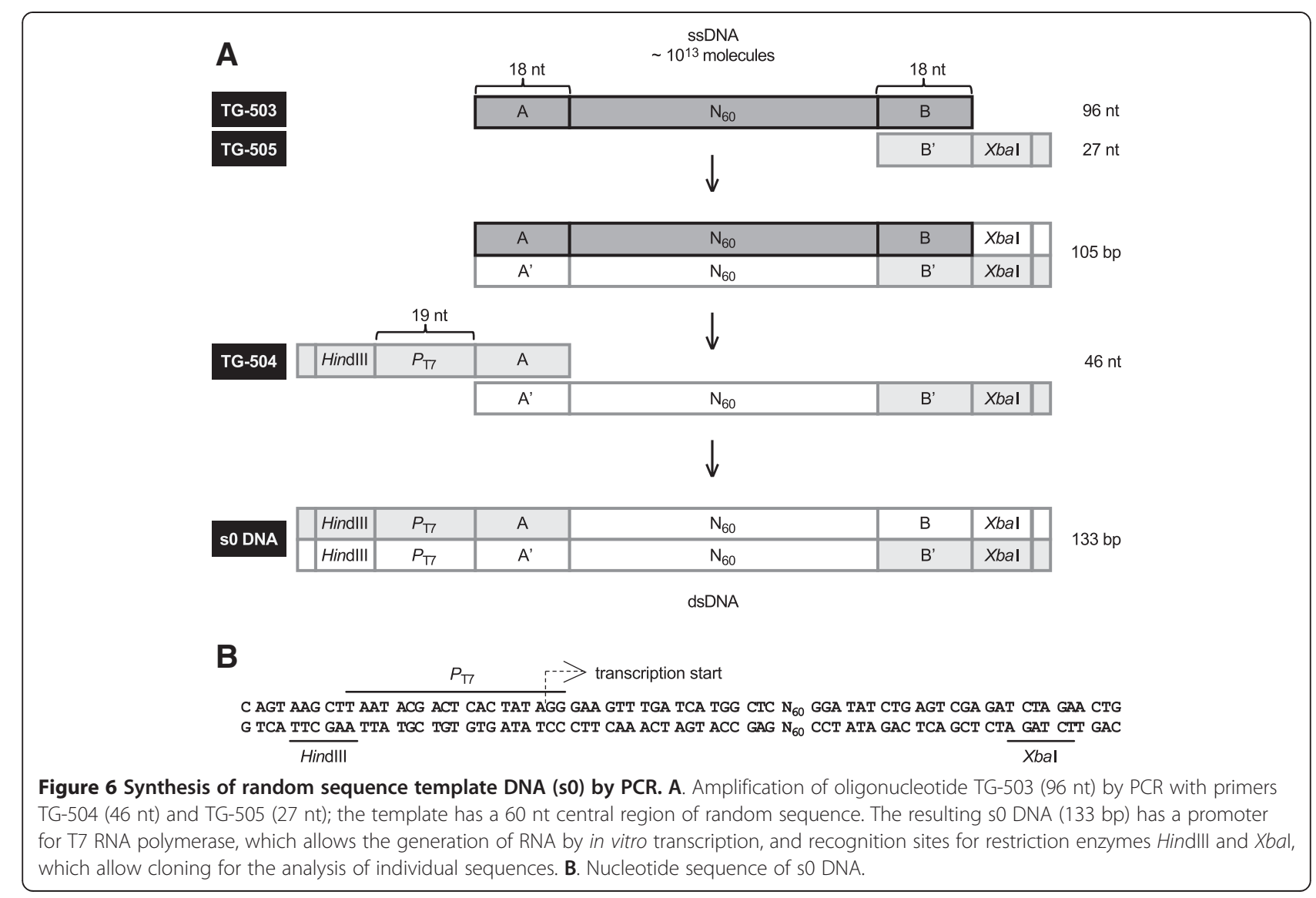


$2.5 \mathrm{~cm}$ ) allowed the separation of RNA molecules that were bound to the protein (retained on the filter) from those that were unable to bind. Filters were washed twice with $200 \mu \mathrm{L}$ of binding buffer. The bound (selected) RNAs were recovered from the filter (cut into $2 \times 2 \mathrm{~mm}$ pieces) by soaking for $1 \mathrm{~h}$ at room temperature in $200 \mu \mathrm{L}$ of $10 \mathrm{mM}$ Tris- $\mathrm{HCl}$ $\mathrm{pH} 7.4$ and $400 \mu \mathrm{L}$ of water saturated phenol; RNAs were precipitated using $20 \mu \mathrm{g}$ of glycogen (Roche) as carrier and resuspended in water.

RNAs selected in each cycle were reverse transcribed in one $20 \mu \mathrm{L}$ reaction. Briefly, the RNA was incubated in standard buffer with $0.5 \mathrm{mM}$ each dNTP and 100 pmoles TG-505 for $10 \mathrm{~min}$ at $55^{\circ} \mathrm{C}$ and switched to ice prior to the addition of $200 \mathrm{U}$ of M-MLV reverse transcriptase (Promega) and incubation at $42^{\circ} \mathrm{C}$ for $1 \mathrm{~h}$. Following precipitation, the entire cDNA preparation was amplified in 5 PCR reactions with primers TG-504 and TG-505. The DNA was pooled, precipitated, and full-length molecules were purified from a 3\% Nusieve agarose gel. Enough RNA for the next selection step was generated from this DNA (which was not subjected to XbaI digestion) in 5 in vitro transcription reactions, each with $250 \mathrm{ng}$ of template. Reactions were pooled, nucleic acids were precipitated, and the full-length RNA (107 nt) was purified from polyacrylamide gels, concentrated, and used for the next selection cycle.

\section{Inhibition of sphingomyelinase activity by pools of selected RNA}

Binding reactions were performed as indicated for the selection steps but at protein:RNA molar ratios of $1: 1$, using $100 \mathrm{ng}$ of SMD-Ll1 and $20 \mathrm{ng}$ of SMD-Ll2 per enzymatic assay. Enough protein for a group of assays was prepared for binding in one tube $(25 \mu \mathrm{L}$ per assay) while RNAs from different selected pools were renatured individually in one tube per assay $(25 \mu \mathrm{L})$. The protein was added to the RNA and, after the $10 \mathrm{~min}$ binding step, the protein-RNA mixture was added to $50 \mu \mathrm{L}$ of binding buffer in each well of a 96-well plate, making $100 \mu \mathrm{L}$ of sample over which $100 \mu \mathrm{L}$ of Amplex Red working solution were added to initiate the enzymatic reaction. Sphingomyelinase activity was measured as indicated. Typically, 3 experiments $(n=3)$ were performed in triplicate. For each experiment, the average of blank fluorescent counts was subtracted from individual measurements; triplicates were averaged and expressed as percent of the activity obtained for the protein in the absence of RNA (100\% activity) in that same experiment. Data were subjected to analyses of variance (ANOVA) of repeated measures and the Tukey post-test (GraphPad Prism software).

Cloning of RNA pools and sequencing of individual clones The cDNAs of some RNA pools were cloned in pUC19 (New England Biolabs) using HindIII and XbaI (full transcription units). Clones were sequenced with M13 universal primers in microplate format (Macrogen, USA). Sequence relatedness between clones was analyzed with Clustal W 2.1 [30]. Families of sequences (groups comprising two or more clones) were named with increasing numbers (starting with family \#1 in each cohort) according to the following hierarchy: total number of clones, number of identical clones, lowest clone number (clone name).

\section{Inhibition of sphingomyelinase activity by individual RNA aptamers}

Performed as detailed for pools of selected RNA but at protein:RNA molar ratios of 1:10. Each RNA was generated in several $50 \mu \mathrm{L}$ in vitro transcription reactions using $250 \mathrm{ng}$ of template. Duplex templates were obtained by PCR performed on each plasmid clone with primers TG504 or M13-reverse and TG-505 using $1 \mathrm{mM} \mathrm{MgCl}_{2}$ $\left(2 \mathrm{~min} 94^{\circ} \mathrm{C} / 35\right.$ cycles of $1 \mathrm{~min} 94^{\circ} \mathrm{C}, 2 \mathrm{~min} 60^{\circ} \mathrm{C}, 2 \mathrm{~min}$ $72^{\circ} \mathrm{C} / 10 \mathrm{~min} 72^{\circ} \mathrm{C}$ ). Amplicons were precipitated prior to use as templates. Typical yields were $1 \mu \mathrm{g}$ of DNA per reaction and 2-8 $\mu \mathrm{g}$ RNA per transcription. Full length RNAs were purified as indicated. Large amounts of RNA were alternatively obtained with the TranscriptAid T7 High Yield Transcription Kit (Thermo Scientific). Typically, a single $20 \mu \mathrm{L}$ reaction was carried out for 18 hours at $37^{\circ} \mathrm{C}$ using $250 \mathrm{ng}$ of PCR product as template; yields were $20-80 \mu \mathrm{g}$ of RNA. Following purification, RNAs were concentrated by precipitation.

\section{Abbreviations}

ANOVA: Analysis of variance; PCR: Polymerase chain reaction; SELEX: Selection of ligands by exponential enrichment; SEM: Standard error of the mean; SMD: Sphingomyelinase D.

\section{Competing interests}

The authors declare that they have no competing interests.

\section{Authors' contributions}

AS conceived and designed the study, obtained the funding, cloned selected RNA pools, analysed the sequences, and drafted the manuscript. CS-L and CC-M carried out all work with SMD-LI2 and SMD-LI1 respectively (cloning, purification, SELEX, functional characterization of aptamers and statistical analyses), and revised the manuscript. CS-L prepared most of the figures. All authors participated in the acquisition, analysis and interpretation of data, participated in designing the figures, and read and approved the final manuscript.

\section{Acknowledgements}

We thank Robel Vásquez for his valuable contribution to laboratory work, especially for the preparation of plasmid clones for sequencing and for the synthesis and purification of individual aptamers. We also thank Benjamín Erranz for helpful discussions. Supported by FONDECYT \#1100209 (Fondo Nacional de Desarrollo Científico y Tecnológico, Chile).

Received: 29 July 2013 Accepted: 17 October 2013 Published: 26 March 2014

\section{References}

1. Futrell JM: Loxoscelism. Am J Med Sci 1992, 304:261-267.

2. Hogan CJ, Barbaro KC, Winkel K: Loxoscelism: old obstacles, new directions. Ann Emerg Med 2004, 44:608-624.

3. Swanson DL, Vetter RS: Loxoscelism. Clin Dermatol 2006, 24:213-221. 
4. Schenone H: Cuadros tóxicos producidos por mordeduras de araña en Chile: latrodectismo y loxoscelismo. Rev Med Chil 2003, 131:437-444.

5. Sezerino UM, Zannin M, Kowlaski Coelho L, Gonçalves J Jr, Grando M, Grossemann Mattosinho S, Costa Cardoso JL, von Eickstedt VR, Siqueira França FO, Barbaro KC, Fan HW: A clinical and epidemiological study of Loxosceles spider envenoming in Santa Catarina, Brazil. Trans R Soc Trop Med Hyg 1998, 92:546-548.

6. Chaim OM, Trevisan-Silva D, Chaves-Moreira D, Wille ACM, Pereira Ferrer V, Matsubara FH, Mangili OC, Bertoni da Silveira R, Gremski LH, Gremski W, Senff-Ribeiro A, Saches Veiga S: Brown spider (Loxosceles genus) venom toxins: tools for biological purposes. Toxins (Basel) 2011, 3:309-344.

7. Tambourgi DV, Magnoli FC, van den Berg CW, Morgan BP, de Araujo PS, Alves EW, Dias Da Silva W: Sphingomyelinases in the venom of the spider Loxosceles intermedia are responsible for both dermonecrosis and complement-dependent hemolysis. Biochem Biophys Res Commun 1998, 251:366-373.

8. Fernandes-Pedrosa de M F, de LM JdAl, Gonçalves-de-Andrade RM, van den Berg CW, Ramos CRR, Ho PL, Tambourgi DV: Molecular cloning and expression of functional dermonecrotic and haemolytic factor from Loxosceles laeta venom. Biochem Biophys Res Commun 2002, 298:638-645.

9. Tambourgi DV, Magnoli FC, Von Eickstedt VRD, Benedetti ZC, Petricevich VL, Dias da Silva W: Incorporation of a 35-kilodalton purified protein from Loxosceles intermedia spider venom transforms human erythrocytes into activators of autologous complement alternative pathway. J Immunol 1995, 155:4459-4466.

10. Tambourgi DV, Gonçalves-de-Andrade RM, van den Berg CW: Loxoscelism: from basic research to the proposal of new therapies. Toxicon 2010, 56:1113-1119.

11. Catalán A, Cortes W, Sagua H, González J, Araya JE: Two new phospholipase D isoforms of Loxosceles laeta: cloning, heterologous expression, functional characterization, and potential biotechnological application. J Biochem Mol Toxicol 2011, 25:393-403.

12. de Santi Ferrara Gl, Fernandes-Pedrosa de M F, de LM J-d-A I, Gonçalves-deAndrade RM, Portaro FCV, Manzoni-de-Almeida D, Murakami MT, Arni RK, van den Berg CW, Ho PL, Tambourgi DV: SMase II, a new sphingomyelinase D from Loxosceles laeta venom gland: molecular cloning, expression, function and structural analysis. Toxicon 2009, 53:743-753.

13. Olvera A, Ramos-Cerrillo B, Estévez J, Clement H, de Roodt A, Paniagua-Solís J, Vázquez H, Zavaleta A, Salas Arruz M, Stock RP, Alagón A: North and South American Loxosceles species: development of a polyvalent antivenom with recombinant sphingomyelinases $D$ as antigens. Toxicon 2006, 48:64-74.

14. Araujo SC, Castanheira P, Alvarenga LM, Mangili OC, Kalapothakis E, ChávezOlórtegui C: Protection against dermonecrotic and lethal activities of Loxosceles intermedia spider venom by immunization with a fused recombinant protein. Toxicon 2003, 41:261-267.

15. Ramos-Cerrillo B, Olvera A, Odell GV, Zamudio F, Paniagua-Solís J, Alagón A, Stock RP: Genetic and enzymatic characterization of shingomyelinase D isoforms from the North American fiddleback spiders Loxosceles boneti and Loxosceles reclusa. Toxicon 2004, 44:507-514.

16. Senff-Ribeiro A, da Silva PH, Chaim OM, Gremski LH, Paludo KS, Bertoni da Silveira R, Gremski W, Mangili OC, Sanches Veiga S: Biotechnological applications of brown spider (Loxosceles genus) venom toxins. Biotechnol Adv 2008, 26:210-218.

17. Manzoni de Almeida D, Fernandes-Pedrosa de M F, de Andrade RM G, Marcelino J, Gondo-Higashi H, de LM JdAl, Ho PL, van den Berg C, Tambourgi DV: A new anti-loxoscelic serum produced against recombinant sphingomyelinase D: results of preclinical trials. Am J Trop Med Hyg 2008, 79:463-470

18. Alvarenga LM, Martins MS, Moura JF, Kalapothakis E, Oliveira JC, Mangili OC, Granier C, Chávez-Olórtegui C: Production of monoclonal antibodies capable of neutralizing dermonecrotic activity of Loxosceles intermedia spider venom and their use in a specific immunometric assay. Toxicon 2003, 42:725-731.

19. Guilherme P, Fernandes I, Barbaro KC: Neutralization of dermonecrotic and lethal activities and differences among 32-35 kDa toxins of medically important Loxosceles spider venoms in Brazil revealed by monoclonal antibodies. Toxicon 2001, 39:1333-1342.
20. Barbaro KC, Knysak I, Martins R, Hogan C, Winkel K: Enzymatic characterization, antigenic cross-reactivity and neutralization of dermonecrotic activity of five Loxosceles spider venoms of medical importance in the Americas. Toxicon 2005, 45:489-499.

21. Gomez HF, Miller MJ, Waggener MW, Lankford HA, Warren JS: Antigenic cross-reactivity of venoms from medically important North American Loxosceles spider species. Toxicon 2001, 39:817-824.

22. Tambourgi DV, Fernandes-Pedrosa de M F, van den Berg CW, Gonçalves-deAndrade RM, Ferracini M, Paixão-Cavalcante D, Morgan BP, Rushmere NK Molecular cloning, expression, function and immunoreactivities of members of a gene family of sphingomyelinases from Loxosceles venom glands. Mol Immunol 2004, 41:831-840.

23. Keefe $A D$, Pai $S$, Ellington A: Aptamers as therapeutics. Nat Rev Drug Discov 2010, 9:537-550.

24. Stoltenburg R, Reinemann C, Strehlitz B: SELEX-A (r)evolutionary method to generate high-affinity nucleic acid ligands. Biomol Eng 2007, 24:381-403.

25. Murakami MT, Fernandes-Pedrosa MF, Tambourgi DV, Arni RK: Structural basis for metal ion coordination and the catalytic mechanism of sphingomyelinase D. J Biol Chem 2005, 280:13658-13664.

26. Lauridsen LH, Veedu RN: Nucleic acid aptamers against biotoxins: a new paradigm toward the treatment and diagnostic approach. Nucleic Acid Ther 2012, 22:371-379.

27. Citartan M, Gopinath SCB, Tominaga J, Tan S-C, Tang T-H: Assays for aptamer-based platforms. Biosens Bioelectron 2012, 34:1-11.

28. Xiong A-S, Yao Q-H, Peng R-H, Duan H, Li X, Fan H-Q, Cheng Z-M, Li Y: PCR-based accurate synthesis of long DNA sequences. Nat Protoc 2006, 1:791-797.

29. Sapag A, Draper DE: In vitro evolution used to define a protein recognition site within a large RNA domain. Bioorg Med Chem 1997, 5:1097-1105.

30. Thompson JD, Higgins DG, Gibson TJ, Clustal W: Improving the sensitivity of progressive multiple sequence alignment through sequence weighting, position-specific gap penalties and weight matrix choice. Nucleic Acids Res 1994, 22:4673-4680.

doi:10.1186/0717-6287-47-2

Cite this article as: Sapag et al:: First report of in vitro selection of RNA aptamers targeted to recombinant Loxosceles laeta spider toxins. Biological Research 2014 47:2.

\section{Submit your next manuscript to BioMed Central and take full advantage of:}

- Convenient online submission

- Thorough peer review

- No space constraints or color figure charges

- Immediate publication on acceptance

- Inclusion in PubMed, CAS, Scopus and Google Scholar

- Research which is freely available for redistribution 